\title{
OS PROCESSOS DE NEGOCIAÇÃO DOS LUGARES SOCIAIS DE PROFESSORA E ALUNOS NO CONTEXTO DA ESCOLARIZAÇÃO FORMAL
}

\author{
Adriano Henrique Nuernberg*
}

\begin{abstract}
RESUMO: A análise da relação entre contextos sociais e modos de (inter)subjetividade implica considerar o fato de que os sujeitos engendram suas açôes pautando-se nos lugares sociais que ocupam. Nesse estudo pretendeu-se analisar, a partir do movimento de negociação dos sentidos relacionados às posições enunciativas assumidas, como os sujeitos significam tais lugares sociais. Para tanto, com base em uma análise microetnográfica de episódios interativos registrados por meio de filmagens de um contexto da escolarização formal, verificou-se o embate em torno dos lugares sociais de professora e alunos, posto na arena da produção de sentidos. Constatou-se que os processos de significação destes lugares apresentam-se pautados pelas contradições históricas e culturais que marcam as relações sociais de ensinar e aprender, dentre elas as dicotomias de saber e não-saber. Tensão, oposição e resistência marcaram as tramas discursivas analisadas, revelando matizes da produção de sentidos dos lugares sociais de aluno e professora.
\end{abstract}

Palavras-chave: Lugar social. Educação formal. Linguagem. Enunciação. Sujeito.

\section{THE NEGOTIATION PROCESS FROM THE TEACHER AND STUDENTS' SOCIAL STANDS IN THE CLASSROOM.}

ABSTRACT: The analysis of the relation between social contexts and forms of intersubjectivity has to consider the fact that the actions of the subjects are a result of their social stand. This study aims at analyzing what meanings subjects give to their social stands when negotiating the signification of the enunciative position they assume. In order to do so, episodes of interaction between teachers

Doutorando no Programa Interdisciplinar em Ciências Humanas da UFSC e professor do Curso de Psicologia da UNISUL.E-mail: adrianoh@cfh.ufsc.br

Educ. Soc., Campinas, vol. 23, n. 81, p. 229-243, dez. 2002

Disponível em <http://www.cedes.unicamp.br> 
and students were videotaped in a formal school context and a microetnographic method was used to analyze the data obtained. A clash between the teacher and the students' social stands was observed in the arena of the production of meaning. The processes of making such social stands meaningful were shown to be lying on historical and cultural contradictions that influence social relations between teaching and learning, among which is the dichotomy knowing/not knowing. The analyzed verbal exchanges are marked by tension, opposition, and resistance, revealing variations in the production of meaning from the teacher and students' social stand.

Key words: Social stand. Formal education. Language. Enunciation. Subject.

\section{Introdução}

$\mathcal{V}$ ma boa parte dos estudos científicos decorre de perguntas que instigam o pesquisador a se lançar em busca de dados empíricos que lhe ajudem a encontrar respostas satisfatórias às questões e hipóteses iniciais. Não é o caso deste estudo, cuja pergunta investigada foi formulada posteriormente à fase de coleta de dados, no caso, depois de realizadas filmagens em vHS do contexto pedagógico de uma turma de ensino fundamental da rede pública municipal de Florianópolis (sc).

No exaustivo trabalho de mapear e caracterizar as tramas discursivas daquele contexto de sala de aula, ficou claro que professora e alunos não negociavam apenas saberes, mas também os sentidos dos lugares simbólicos que ocupavam naquelas relaçôes: o lugar social de professora e o de aluno. Nas busca de subsídios para compreender o que se passava naquele contexto, verificou-se que a literatura a respeito, embora oferecesse elementos para compreender como os sujeitos produzem novos sentidos às posições simbólicas que ocupam, estava mais preocupada em mostrar que tais posições atuam na negociação dos saberes, destacando fundamentalmente que “(...) de fato, as palavras não significam por e em si mesmas, mas por quem fala, ou pelos lugares sociais que o sujeitos falantes ocupam no jogo discursivo" (Smolka, 1992, p. 332).

No estudo daquelas trocas sociais constatou-se a necessidade de investigar como professora e alunos significavam os lugares sociais que assumiam em sala de aula e, concomitantemente, como esses enunciados eram significados pelas mesmas posições simbólicas. Estes dois movimentos revelavam contradições e rupturas postas na relação do sujeito com os contextos culturais. Ora professora e alunos eram legítimos 
representantes dos lugares sociais que assumiam, ora se distanciavam destes, afirmando sua autonomia em relação às expectativas em jogo no contexto pedagógico.

Adota-se aqui o pressuposto de que a fala dos sujeitos realiza-se a partir de uma posição enunciativa determinada, de acordo com o contexto do qual participa. A identidade social é, portanto, constituída pelos diversos lugares sociais por meio dos quais os sujeitos são reconhecidos, seja de professora, aluno, pai, mãe, político, padre etc. Os lugares sociais, por sua vez, atravessam-se de modo a classificar e valorar as falas e ações por meio das mais diversas categorias sociais: gênero, etnia, classe social, religião, geração e profissão. Dessa forma que os sujeitos se posicionam socialmente, atendendo, negando e significando as expectativas que lhes cabem a partir destas categorias sociais.

Isso colabora para que os enunciados de cada sujeito sejam constituídos pelo lugar simbólico que ocupa, de modo que

Quando se diz algo, alguém o diz de algum lugar da sociedade para outro alguém também de algum lugar da sociedade e isso faz parte da significação. Como é exposto por Pêcheux, há nos mecanismos de toda formação social, regras de projeção que estabelecem a relação entre as situações concretas e as representaçōes dessas situaçōes no interior do discurso. É o lugar assim compreendido, enquanto espaço de representaçôes sociais, que é constitutivo da significaçáo discursiva. (Orlandi, 1987, p. 26)

Os efeitos da significação a partir dos lugares sociais não se resumem, no entanto, a esse aspecto. Se por um lado o lugar social significa os enunciados de um sujeito, esse também produz sentidos acerca da posição simbólica que assume. Ademais, se a ideologia que pauta estas significações o afeta, é de forma singular (Orlandi, 1996).

No caso específico do contexto de sala de aula, foco do presente estudo, é também importante lembrar que “(...) pela posição do professor na instituição (como autoridade convenientemente titulada) pela apropriação do cientista feita por ele, dizer e saber se equivalem, isto é, diz que $z=$ sabe $z$. E a voz do saber fala no professor" (Orlandi, 1987, p. 21). Seus enunciados têm o status de verdade, assim como a forma de organizar o espaço pedagógico nas atividades. As atitudes e formação do(a) professor(a), contudo, não chegam a garantir o reconhecimento deste(a) enquanto fonte de saber/verdade: é preciso que afirme também certo modo de produção discursiva, ou seja, uma forma particular de organização/formação dos enunciados. 
Ressalta-se, nesse âmbito, o fato de que nessa trama discursiva os próprios sujeitos estão se constituindo, por meio dos jogos de poder e saber que tramitam em cada esfera social. Nesse embate de estratégias de dominação e de resistência é que o sujeito se constitui, marcado pelas verdades, normas e contradições com que trava contato.

Resgatando-se as contribuições de Michel Foucault para análise dessas questões, obtemos argumentos sobre a relação saber/poder que complementam os já colocados até aqui. Em sua busca de identificação das condições históricas e epistemológicas que promoveram a instituição do homem como objeto de saber, esse autor propõe uma correlação entre a constituição de um campo de saber e a instauração de práticas discursivas que correspondem e/ou legitimam estratégias de poder (Machado, 1981; Siqueira, 1988). Nessa perspectiva, os diversos campos do conhecimento podem ser tomados como discursos ${ }^{1}$ constituídos no intuito do estabelecimento de exercícios de dominação em torno daquilo que se propõe a conhecer. Tais discursos, como é o caso das ciências, assumem critérios de verdade e se difundem com esse caráter por meio das grandes instituições (Foucault, 1993b, p. 13). Desse modo, em conformação com o exposto sobre os lugares sociais, pode-se dizer que os enunciados dos que representam os diversos campos do conhecimento adquirem, em nossa sociedade, status de verdade, corroborando para a manutenção dos dispositivos de poder existentes.

Nessa mesma linha de investigação, Foucault (1986) propõe-se a identificar as estratégias das ciências de aparecerem como unidades ou discursos uniformes em torno de um objeto de estudo, como no caso das descrições sobre a loucura feitas pela psiquiatria. Em suma, sua perspectiva visa empreender um sentimento de inquietude frente a essa aparente unidade, à medida que, superando-se a análise de superfície, o que se revela é a descontinuidade, a ruptura dos enunciados. Para tanto, Foucault propõe o conceito de formações discursivas, que se refere ao processo dos enunciados constituírem uma regularidade por meio de escolhas temáticas, submetendo-se a regras de formação, a determinadas "condições de existência em uma dada repartição discursiva" (Foucault, 1986 , p. 44), de modo que se institui "um conjunto de práticas que regulam o que pode e deve ser dito em uma dada posição e em uma dada conjuntura" (Smolka, 1991, p. 57).

Com base nas questôes postas por Foucault, concebe-se o discurso do sujeito ${ }^{2}$ como lacunar, disposto a inúmeras possibilidades (descontínuas) de realização. Sua inserção em lugares sociais específicos, entretanto, institui o enquadre de seu discurso às condições de formação 
específicas, ou seja, às "formas de coexistência entre os enunciados" do sujeito (idem, ibid., p. 79). Deste modo, para Foucault, o sistema de formação,

(...) prescreve o que deve ser correlacionado em uma prática discursiva, para que esta se refira a tal ou qual objeto, para que empregue tal ou qual enunciação, para que se utilize tal ou qual conceito, para que se organize tal ou qual estratégia. Definir em sua individualidade singular um sistema de formação é, assim, caracterizar um discurso ou um grupo de enunciados pela regularidade de uma prática. (Foucault, 1986, p. 82)

O que se pretende com essas questões é acrescentar subsídios para se compreender as enunciações produzidas pelos sujeitos nas relaçóes sociais. Seguindo o que propóe Foucault, parece ser prudente verificar a relação de determinadas falas com o lugar social que o sujeito ocupa, concebendo-se esta condição como referencial para a organização das práticas discursivas que transitam em sala de aula. A questão posta, em síntese, diz respeito à possibilidade de se falar da existência de práticas discursivas no âmbito pedagógico. Ou, conforme Smolka (1991, p. 57), “(...) os interlocutores, a situação, o contexto sócio-histórico, as imagens que os interlocutores se fazem, como eles representam e se representam na situação etc. configuram as 'condições de produção' do discurso que marcam e constituem o sentido de uma seqüência verbal”.

Com base nesses pressupostos, objetiva-se verificar como se configuram os processos de significação em torno dos lugares sociais do contexto da escolarização formal. O modo como os sujeitos assumem tais posições enunciativas resulta do estabelecimento de fatores que se expressam nos seus enunciados. Por meio da análise de um pequeno episódio ocorrido em sala de aula, pretende-se investigar uma parcela importante dos sentidos produzidos em relação aos lugares de professora e alunos assumidos nas relações de ensinar e aprender no contexto da escolarização formal. Vale dizer que algumas generalizações serão promovidas com base na totalidade das análises feitas em um estudo anterior das filmagens que originaram o episódio aqui apresentado (Nuernberg, 1999).

\section{O episódio ${ }^{3}$}

Nesse episódio está em curso uma atividade de correção de um exercício de separação silábica realizado em outra aula. Em dado instante, 
a palavra "providências", uma das que apresentam suas sílabas divididas no texto, marca um momento de dúvida na resolução do exercício. A atitude da professora dá indicativos de que esta não tem certeza quanto à separação da última sílaba, o que a leva a recorrer a outras indagações com os alunos sobre as características dessa palavra e as regras de separação silábica. Como último recurso, solicita a uma aluna que vá até à secretaria e consulte a diretora da escola, que também é professora.

1. (Prof): Só uma coisa: pergunta para Maria Antônia se a palavra 'providência' pode ser separado o 'ci' do 'a'.

2. (Pedro): Uma professora perguntar pra outra...

3. (Prof): É que a diretora [da escola] é formada em Língua Portuguesa, então é mais fácil saber.

4. (Pedro): Ah, tá.

Vale destacar o turno número 2, onde um dos alunos expressou um certo estranhamento, revelador de que para ele não haveria razão para tal consulta, pois ambas são professoras e, portanto, compartilham, ao menos em tese, do mesmo nível de conhecimento. Como se o "natural" fosse apenas o aluno perguntar para a professora. Tal situação permite, para fins de análise, identificar a representação que esse aluno possui do lugar do saber no contexto pedagógico, ou seja, da autoridade docente. Soma-se a esses dados o fato de que foi preciso que a professora justificasse sua consulta com a informação sobre a especialização de sua colega para que o aluno "desarmasse" seu estranhamento e aceitasse a situação, dizendo "ah, tá...”.

Depois de alguns minutos, observa-se o momento em que a aluna que havia consultado a diretora retorna e relata a informação obtida:

5. (Prof): Jaime! Olha só... / (Cátia): [retorna a sala] Não... [transmitindo a resposta dada por Maria Antônia à pergunta sobre a separação de sílabas]

6. (Prof): Não pode? Então essa separação não tá correta. [apagando a separação pro-vi-dên-ci-a]

7. (Als): [vaiando em voz alta] Uuuuuuuuu...

8. (Prof): [Para e olha para turma] Olha aqui: se tivesse na sala uma pessoa que nunca tivesse feito um erro, eu poderia admitir esse tipo de atitude. 
9. (Pedro): Isso mesmo!

10. (Als): Êêêe....

11. (Márcia): É, mas tu também fizesse, querido...

Esta fração do episódio sugere um momento de tensão nessas relações, sendo a professora posta em xeque pelos alunos, devido ao seu "erro". A vaia é dirigida à docente, que reage através de um discurso moral (turno 8). Por outro lado, um dos alunos, Pedro, após a professora ter chamado a atenção da turma, afirma estar em concordância com o discurso desta e com a sua possibilidade de "erro". Sua atitude, no entanto, é logo colocada em questão por uma colega (turno 11), que ironiza a ambigüidade ${ }^{4}$ das posições que este assumiu.

\section{Discussão}

Um primeiro aspecto a se considerar é a possibilidade concreta de se compreender os sujeitos por meio dos lugares sociais que assumem nas relações em sala de aula, a saber, o de professora e aluno. Sendo assim, ao se tomar a atividade e o discurso dos sujeitos, concebe-se estes levando-se em conta suas posiçóes de professora e de aluno e a forma como assumem essas posições enunciativas. Sem aprofundar nos fatores constituintes dessa condição, o foco se dá em como esta é assumida, partindo da premissa de que

Nunca poderemos falar "de lugar nenhum", dado que podemos falar (ou mais amplamente agir) somente invocando os meios mediacionais que estão disponíveis no kit de ferramentas culturais fornecido pelo contexto sociocultural no qual operamos (...). (Wertsch et al., 1998, p. 31)

Parte-se, ademais, do pressuposto de que os próprios lugares sociais se apresentam em constante movimento de significação, o que lhes proporciona o status de processos (re)produzidos entre e pelos sujeitos. A própria preservação destes lugares sociais no espaço pedagógico implica que os sujeitos enunciem e atuem conforme as expectativas e compromissos de suas recíprocas posições. No caso da professora, como acima foi exposto, existe a pressuposição e a expectativa de que esta detém o domínio sobre o conhecimento que transita nas atividades que coordena, o que se funda numa relação hierárquica onde ela é autoridade constituída de saber. Trata-se da 
efetivação de um "contrato" de reconhecimento mútuo pautado pelas trocas sociais de conhecimento e que se realiza a partir de um modo característico de enunciados, de professor e de aluno, de padróes de relação que são exclusivos do contexto pedagógico.

Por meio dos episódios, vê-se, no entanto, um momento em que se apresenta uma lacuna nessas expectativas: a professora apresenta-se como sujeito de "não saber" e necessita consultar uma colega para resolver uma dúvida. Por outro lado, a reação de estranhamento do aluno e a necessidade da professora em apresentar uma justificativa confirmam a ruptura da expectativa posta pelo respectivo lugar social. Justifica-se esse acontecimento pelo fato de que

(...) a criança, ao chegar na escola, já tem uma determinada noção de autoridade cuja lógica específica não pode divergir da lógica que ela já possui, sob pena de se tornar incompreensível para ela. Esta lógica é a de que o professor é a fonte de conhecimentos e o aluno, uma tábula rasa, assim como na família, a lógica é a de que os pais mandam e os filhos obedecem. (Contador, apud Guareschi, 1990, p. 96)

É nessa "lógica" que se pautam o estranhamento do aluno e a justificativa da professora que, em resposta à indagação de Pedro e para garantir sua posição, desloca a resolução da dúvida para um campo de saber que não lhe pertence e que, em princípio, não tem obrigação de dominar. Trata-se de uma "lógica" histórica e culturalmente constituída que se presentifica por meio das especificidades desse contexto e é mantida pelos sujeitos que a protagonizam. Afinal, diante do estranhamento do aluno, esses lugares do "saber" e "não saber" não poderiam se constituir como objeto de reflexão?

Essa trama se complexifica nos turnos seguintes ( 6 a 11), onde se observa a turma vaiando a professora, estabelecendo-se, assim, um momento de maior tensão. Constatando-se o abalo na base do lugar social da professora - o saber -, abre-se espaço para que haja o desafio à autoridade da professora e a possibilidade dela ser vaiada. A vaia, portanto, representa um momento em que o status do lugar social da professora - o do "saber" - é questionado. Por seu intermédio, são reproduzidos alguns dos preconceitos e estereótipos sociais necessários à manutenção do "normal", do socialmente correto e esperado. $\mathrm{O}$ riso e a vaia, ao produzirem o efeito do constrangimento, figuram como mecanismos de vigilância fundados na necessidade de se prezar pela precisão e constância daquilo que é institucional, sedimentado e previsto. Por outro lado, podem ser vistos como um modo de confrontar 
e resistir à figura de autoridade da professora. Ao mesmo tempo, revelam os significados postos no contexto a respeito do "erro" e do "não saber", bem como os sentidos produzidos em relação aos lugares sociais envolvidos nas atividades de ensinar e aprender.

Vale destacar que o que faz a professora, em relação à vaia que recebe dos alunos, diferencia-se sobremaneira da atitude que assume (calar) quanto o aviltado foi algum aluno, em episódios outros. Seu discurso, ainda que tenha negado o caráter individual do "erro", o qual justificaria o aviltamento de uns sobre outros, armou-se com um tom moral e disciplinador que se confronta com a pretensa "neutralidade" de momentos anteriores, em que os alunos riam ou ridicularizavam os equívocos ou "erros" de seus colegas. Analisandose o contexto em que a professora traz esse discurso, no qual sua posição social é posta em xeque, o tom disciplinador lhe possibilita "anular" o efeito da vaia e, ao mesmo tempo, reafirmar-se como autoridade. Figura-se, portanto, o sentido de que o erro corresponde ao lugar do aluno e, eventualmente, da professora, sendo pertencente ao território de eventos que remetem à posição de aprendiz.

$\mathrm{O}$ acontecimento evidenciado nestes turnos mostra o quanto a relação dos sujeitos com tais lugares sociais é complexa e contraditória. Não só a atitude da professora de apoiar-se no saber de uma colega evidenciou um relativo abalo no lugar de autoridade de saber/poder, mas também os próprios alunos desafiam a dimensão institucional de tais lugares sociais ao vaiarem a professora.

Entretanto, ao se superar o olhar "adultocêntrico", ao qual se vislumbra que apenas o adulto comanda as relações pedagógicas, verifica-se que a todo tempo os alunos assumem um lugar diferente do que lhe é imputado socialmente, pervertendo a lógica das expectativas em jogo nessas relações. Situações de conflito entre os alunos, além das típicas formas de saída da atividade observadas (ir ao banheiro, apontar o lápis, conversar com colega, olhar a rua) e também as não-observáveis, como o devaneio, ilustram os vários modos de estabelecimento desta descontinuidade.

Numa abordagem do discurso pautada pela obra de Foucault, a análise destas questôes destacaria este aspecto da descontinuidade como condição do acontecimento discursivo. Contudo,

Não se trata, bem entendido, nem da sucessão dos instantes do tempo, nem da pluralidade dos diversos sujeitos pensantes; trata-se de cesuras que rompem o instante e dispersam o sujeito em uma pluralidade de posiçóes e 
funções possíveis. Tal descontinuidade golpeia e invalida as menores unidades tradicionalmente reconhecidas ou as mais facilmente contestadas: $\mathrm{o}$ instante e o sujeito. E, por debaixo deles, é preciso conceber entre essas séries descontínuas relações que não são da ordem da sucessão (ou da simultaneidade) em uma (ou várias) consciência; (...) Enfim, se é verdade que essas séries discursivas e descontínuas têm, cada uma entre certos limites, sua regularidade, sem dúvida, não é menos possível estabelecer entre os elementos que as constituem nexos de casualidade como categoria na produção dos acontecimentos. (Foucault, 1998, p. 58)

Tais apontamentos de Foucault levam a considerar a tese de que os discursos, em relação aos lugares sociais, implicam o constante trânsito da regularidade para a descontinuidade, não de modo lógico, mas casual. Reside aí um ponto-chave das análises de Foucault: o de ir além da simples busca de um sentido lógico do discurso. Todavia, para o presente estudo, o que interessa é a constatação de que, atravessando os lugares sociais e a regularidade de enunciação que estes admitem, existem o acaso e a ruptura.

\section{Considerações finais}

Esse estudo teve como objetivo investigar os sentidos produzidos em torno dos lugares sociais de professora e alunos no contexto da escolarização formal. Seu ponto de partida foi a constatação de que os sujeitos (professora e alunos) falavam a partir de posições enunciativas que remetiam a análise às especificidades do contexto cultural, sugerindo o desdobramento das vozes explicitadas nos discursos. Os enunciados, assim, mostraram ser constituídos nas/pelas circunstâncias históricas dos lugares sociais ocupados pelos sujeitos e por suas características singulares.

A dialogia, como condição da enunciação, viabiliza a compreensão dialética que pauta a abordagem sobre os discursos aqui desenvolvida. Sendo a significação produzida na interlocução, como síntese da relação de tensão (de sentidos) posta entre locutor e audiência, compreende-se que a significação dos lugares sociais segue o princípio da dialogia ${ }^{5}$ na elaboração de sentidos. Essa compreensão dialética/dialógica é exercitada também ao se desenvolver a tese de que os lugares sociais aqui analisados (ou o modo como os sujeitos os assumem) em sala de aula são mutuamente constitutivos.

A complexidade dos processos de significação dessas posições enunciativas explicita-se, inclusive, à medida que se parte da tese de 
que o lugar social de professora implica a existência de outro lugar "audiência", por meio do qual se referencia, sendo essa uma condição constituinte dos sentidos produzidos acerca desta posição enunciativa. Ou seja, o lugar social de professora é constituído pelo lugar social de aluno e vice-versa, articulando-se na relação de reconhecimento mútuo que se efetiva nas trocas sociais do espaço pedagógico. Constatou-se, inclusive, a relação de tais sentidos com a busca de manutenção da hierarquia entre professora e alunos, marca destacada do modo como os sujeitos compatibilizam seus respectivos territórios de atuação em sala de aula.

Verificou-se essa condição também no episódio analisado, por meio das rupturas estabelecidas na quebra da expectativa dos alunos de que a professora é fonte absoluta de saber e da caracterização do erro como exclusivo do lugar de aluno. A ruptura da professora em relação a seu lugar pode ter levado, assim, os alunos a fazerem o mesmo por meio da vaia. Em razão disso, concorda-se com Foucault (1993), para quem a existência de movimentos de resistência justifica o uso de estratégias de controle e disciplinamento, sendo, portanto, uma condição para o estabelecimento de relaçôes atravessadas pela trama do poder.

Posto que o aluno historicamente ocupa o lugar do a-luno, melhor dizendo, do "sem luz", compreende-se que a fonte "luminosa" do conhecimento aparece histórica e culturalmente na figura do docente. É com base nesse pressuposto de nossa cultura que se autorizam determinadas práticas características desse contexto, tais como as autoritárias, por vezes veladas e supostamente justificáveis pela posição de saber que o professor representa. Todavia, cumpre notar que as estratégias pedagógicas incluem por vezes a condição de negação do saber dos alunos com vistas a estabelecer sua aprendizagem e, portanto, promover o desenvolvimento (Góes, 1997).

Essa questão da relação saber/poder, vinculada ao interjogo dos lugares sociais correspondentes à escolarização formal, adquiriu nuanças interessantes nos episódios analisados. Evocando uma outra autoridade, a diretora (que no caso é formada em Letras), a professora relaciona o saber à condição de formação, reafirmando a relação entre o poder e os campos de conhecimento e mantendo, desta forma, o seu próprio lugar de saber/poder. Legitima-se, assim, a relação de propriedade de um conhecimento a uma determinada área da ciência, da qual a escola possui representantes.

Sugere-se, a título de análise, que o efeito dessas enunciações é o estreitamento da relação saber e poder, que regula, legitima e 
autoriza os enunciados dos sujeitos. Trata-se de um dos aspectos da questão da formação discursiva a que se refere Foucault (1986), onde o discurso é concebido, sob o ponto de vista de sua compleição enunciativa, como uma "unidade controlada", a qual esse estudo relaciona com a circunstância do lugar social assumido pelo sujeito e sua audiência. Critérios de verdade são reproduzidos por meio desses processos, garantindo a manutenção daquilo que é institucional.

Em contrapartida, os movimentos de oposição e resistência aqui destacados explicitam o caráter contraditório dos processos de negociação dos lugares sociais, os quais se vêem atravessados por relações de poder que se evidenciam nos enunciados produzidos pelos sujeitos. Jogos de poder e resistência se apresentaram no episódio, ora mais explicitamente, ora de modo mais velado, por meio do exercício de negociação efetivado pelos sujeitos sobre os territórios de poder a que correspondem os lugares sociais assumidos por estes.

Foi possível identificar, no discurso/prática da docente, o esforço constante de firmar-se como representante da instituição escolar, como legítima autoridade de saber e como coordenadora do processo ensino/ aprendizagem naquele contexto. Em que pesem as atitudes que engendra de negação dos modelos tradicionais de docência, sua ação pedagógica parece bastante presa ao prescritivo, ou seja, a um modo previsível e invariante de atuação profissional nas relações sociais em sala de aula.

Há indicativos para se apontar a necessidade da professora de que os alunos correspondam às suas demandas idealizadas de participação no espaço pedagógico. De fato, em razão das condições institucionais, verificou-se que o compromisso da professora com seu lugar social é mais presente do que o dos alunos com sua respectiva posição simbólica. O que se observa, enfocando as falas e ações dos alunos, é a multiplicidade, a diversidade e riqueza de possibilidades para o lugar social de aluno, ou seja, a desconsideração por parte deles dessa demanda da docente. O que predomina como pauta dos discursos dos discentes é o acaso, a diversidade e a variabilidade. As condições culturais/institucionais que constituem o discurso na professora parecem atingir em menor grau as enunciações dos alunos, de modo que as categorias de análise acima arroladas necessitam ser aprimoradas no estudo das práticas discursivas destes.

Por intermédio da obra de Foucault (1986), temos que a análise do discurso não pode se realizar apenas na obtenção de um sentido de regularidade das enunciações produzidas pelos sujeitos atravessados pelos lugares sociais que ocupam. $\mathrm{O}$ conjunto dos enunciados num discurso, 
como o autor demonstrou na análise dos campos disciplinares de saber, é marcado por descontinuidades, rupturas e lacunas que são próprias do "acontecimento discursivo" e que remetem a condições históricas, econômicas e sociais existentes. Sendo assim, procurou-se salientar tanto o momento em que se observam as falas marcadas pela posição enunciativa assumida pelos sujeitos, impondo certa regularidade na composição enunciativa, quanto o momento em que essa continuidade se dissolve no movimento das relaçóes sociais analisadas.

A contribuição desse estudo, portanto, reside em apontar para a necessidade de se conceber determinados aspectos da relação dos sujeitos com os lugares sociais assumidos. Nesse caso, cumpre notar a importância de pelo menos dois sentidos de análise dessas trocas sociais: dos discursos dos sujeitos sendo significados pelos lugares sociais que assumem e dos sujeitos produzindo sentidos em torno dessas posições enunciativas. São movimentos concomitantes que revelam contradições e rupturas postas na relação do sujeito com os contextos culturais. No caso, trata-se de um contexto institucional, cujas trocas sociais nele presentes implicam a existência de diferentes graus de hierarquia.

Por fim, destaca-se que, ao se propor o estudo dos processos de significação desses lugares sociais, enfatiza-se a importância da relação do funcionamento psicológico consciente com os cenários socioculturais, tendo em vista o processo de constituição do sujeito (Wertsch, 1991). Compreende-se que o sujeito se regula pautando sua atividade nas condiçốes materiais que se apresentam no contexto em que produz sua existência e subjetividade.

No âmbito da escolarização formal, verificou-se a presença de lugares simbólicos de referência, a partir de onde sujeitos falam e produzem conhecimento. Todavia, ainda falta muito para compreendermos todos os meandros do processo que tecem essa trama, pois, como destaca Smolka (1991, p. 57), "entre as contingências do dizer e o momento de realização da enunciação concreta e única, fica muito ainda por ser investigado (...)”. Considerar essas múltiplas circunstâncias da produção dos discursos leva a salientar a complexidade das trocas sociais, que não podem ser reduzidas a simples relações interpessoais. Professora e alunos, desse modo, constituem-se/são constituídos como sujeitos, que realizam sua atividade pautando-se nas marcas históricas e culturais das posiçóes que assumem nesse contexto, ao mesmo tempo em que são agentes produtores destas.

Recebido em abril de 2002 e aprovado em maio de 2002. 


\section{Notas}

1. Foucault (1986, p. 135) traz a noção do discurso como "um conjunto de enunciados, na medida em que se apóiem na mesma formação discursiva (...)", sendo "constituído de um número limitado de enunciados para os quais podemos definir um conjunto de condições de existência”.

2. É digno de nota que os autores da abordagem histórico-cultural (Wertsch, Smolka, Góes, entre outros) e Foucault têm uma compreensão distinta sobre o sujeito. Ao se resgatar a contribuição de ambas as perspectivas, não se quer afirmar nenhuma complementaridade ou coincidência entre as mesmas, apenas fazer uso de suas análises para salientar a complexidade das relações sociais no processo de constituição do sujeito.

3. A forma de apresentação do episódio é baseada em Smolka (1991).

4. Refere-se, assim, ao fato deste mesmo aluno "estranhar" o não saber da professora e aqui admitir essa possibilidade.

5. O princípio da dialogia, na perspectiva de Bakhtin, estabelece que a natureza da enunciação, isto é, do ato de fala, é dialógica, ou seja "Na realidade, toda palavra comporta duas faces. Ela é determinada tanto pelo fato de que procede de alguém, como pelo fato de que se dirige para alguém. Ela constitui justamente o produto da interação do locutor e do ouvinte" (1995, p. 113).

\section{Referências bibliográficas}

BAKHTIN, M. Marxismo e filosofia da linguagem. São Paulo: Hucitec, 1995.

FOUCAULT, M. Arqueologia do saber. 2. ed. Rio de Janeiro: ForenseUniversitária, 1986.

FOUCAULT, M. Vigiar e punir: história da violência nas prisões. Petrópolis: Vozes, 1993.

FOUCAULT, M. Microfisica do poder. 11. ed. Rio de Janeiro: Graal, 1993 b.

FOUCAULT, M. A ordem do discurso. 4. ed. São Paulo: Loyola, 1998.

GÓES, M.C.R. As relações intersubjetivas na construção de conhecimentos. In: Góes, M.C.R.; SMOLKA, A.L.B. (Orgs.). A significação nos espaços escolares. Campinas: Papirus, 1997.

GUARESCHI, N. Poder, autoridade e a relação professor/aluno: uma revisão de literatura. Psico, Porto Alegre, v. 20, n. 2, p. 85-103, 1990.

MACHADO, R. Ciência e saber: a trajetória da arqueologia de Foucault. Rio de Janeiro: Graal, 1981. 
NUERNBERG, A.H. Investigando a significação dos lugares sociais de professora e alunos no contexto de sala de aula. 1999. 101f. Dissertação (Mestrado) - Centro de Filosofia e Ciências Humanas, Universidade Federal de Santa Catarina, Florianópolis.

ORLANDI, E.P. A linguagem e seu funcionamento: as formas do discurso. 2. ed. Campinas: Pontes, 1987.

ORLANDI, E.P. Interpretação: autoria, leitura e efeitos do trabalho simbólico. Petrópolis: Vozes, 1996.

SIQUEIRA, M.J.T. O exercício do poder disciplinar no cotidiano da escola. 1988. 212f. Dissertação (Mestrado) - Centro de Ciências em Educação, Universidade Federal de Santa Catarina, Florianópolis.

SMOLKA, A.B. A prática discursiva na sala de aula: uma perspectiva teórica e um esboço de análise. Cadernos Cedes, Campinas, v. 20, n. 24, p. 51-65, 1991.

SMOLKA, A.B. Internalização: seu significado na dinâmica dialógica. Educação \& Sociedade, Campinas, v. 13, n. 42, p. 330-334, ago. 1992.

WERTSCH, J.V. Voces de la mente: un enfoque sociocultural para el estudio de la acción mediada. Madrid: Visor, 1991.

WERTSCH, J.V.; DEL RIO, P.; ALVAREZ, A. Estudos socioculturais: história, ação e mediação. In: Wertsch, J.V.; Del Rio, P.; Alvarez, A. (Orgs.). Estudos socioculturais da mente. Porto Alegre: Artes Médicas, 1998, p. 11-38. 